\title{
Manejo da irrigação em cultivares de arroz no sistema pré-germinado
}

\author{
Irrigation management in rice cultivars in the pre-geminated system
}

\author{
Enio Marchezan' Gabriel Adolfo Garcia" Edinalvo Rabaioli Camargo ${ }^{\text {III }}$ \\ Paulo Fabricio Sachet Massoni ${ }^{\mathrm{II}}$ Diego Rost Arosemena ${ }^{\mathrm{II}}$ \\ Ana Paula Binato Beltrão de Oliveira ${ }^{\text {IV }}$
}

\section{RESUMO}

No sistema pré-germinado de cultivo de arroz, a área é inundada antes da semeadura e, cerca de três dias após, promove-se a drenagem inicial para favorecer o estabelecimento das plântulas, ocasionando a perda de água e de nutrientes. Assim, testaram três manejos de irrigação: [M1], retirada da água três dias após a semeadura; [M2], retirada de água aos 30 dias após a semeadura e [M3], sem retirada de água, associados a cultivares de arroz, com o objetivo de avaliar a produtividade do arroz e a perda de nutrientes via água de drenagem. Os manejos testados não influenciaram os parâmetros avaliados na cultura do arroz. Para a produtividade, os valores oscilaram conforme as características de cada ano, obtendo-se médias de 5.100, 9.565 e 7.078kg ha-1 para as safras 2002/03, 2003/04 e 2004/05, respectivamente. Apenas em 2003/04, as cultivares diferiram em produtividade. Nas safras 2002/03 e 2003/04, as perdas de fósforo foram semelhantes entre os tratamentos, mas, em 2004/ 05, ocorreram maiores perdas quando a água foi retirada aos três dias após a semeadura. Para potássio, as maiores concentrações também foram observadas nas amostras de água coletadas aos três dias após a semeadura. Os resultados indicam que deve-se manter lâmina contínua, pois este manejo proporciona a preservação dos nutrientes dentro da lavoura, não afeta a produtividade e reduz o impacto ambiental nos mananciais hídricos.

Palavras-chave: fósforo, potássio, perda de nutrientes, drenagem inicial, Oryza sativa L., produtividade.

\section{ABSTRACT}

In the pre-germinate system, the rice field is flooded before sowing and about three days later, the initial drainage takeplace in order to promote the plants initial growth but there occurs loss of nutrients and water. Then, three irrigation managements have been evaluated: water removal three days after sowing, water removal 30 days after sowing and without water removal, associating three rice cultivars with the objective to measuring rice grains yield, and loos nutrients with water removal. The water managements evaluated have not influenced the rice plant parameters. The grains yield varied according to the year, with an average 5,100, 9,565 and 7,078 $\mathrm{kg} \mathrm{ha}^{-1}$ ha in the years 2002/03, 2003/04 and 2004/05, respectively. Only in 2003/04, the grains yield was different among the rice cultivars. In 2002/03 and 2003/04, the phosphorous nutrient was similar among treatments, but in 2004/05 a great loss occurred when water removed three days after sowing. Concerning potassium, the highest concentrations were observed in water when it was removed three days after sowing. Results demonstrate that a continuous water sheet should be kept to preserve the nutrients within the field since it does not affect the crop yield and reduce the environmental impact of the water bodies.

Key words: phosphorous, potassium, loss of nutrients, initial drainage, Oryza sativa L., productivity.

\section{INTRODUÇÃO}

O sistema pré-germinado de cultivo de arroz irrigado se posiciona como uma alternativa aos demais sistemas utilizados por apresentar peculiaridades de manejo e ainda proporcionar a obtenção de altas produtividades em áreas infestadas por arroz vermelho e preto. Dentre as características deste sistema, estão a inundação da área aproximadamente 20 dias antes da semeadura e também a adoção da drenagem inicial da lavoura, cerca de três dias após a realização da

IDepartamento de Fitotecnia, Centro de Ciências Rurais (CCR), Universidade Federal de Santa Maria (UFSM), 97105-900, Santa Maria, RS, Brasil. Email: emarch@ccr.ufsm.br. Autor para corrêspondência.

IICurso de Agronomia, Departamento de Fitotecnia, UFSM, CCR, Santa Maria, RS, Brasil.

IIIPrograma de Pós-graduação em Agronomia, UFSM, CCR, Santa Maria, RS, Brasil.

${ }^{\text {Iv }}$ Autônoma, Santa Maria, RS, Brasil. 
semeadura, com o objetivo de proporcionar melhor estabelecimento inicial às plântulas de arroz. LAURETTI et al. (2001) citam que a “turvação” da água antes da semeadura prejudica o desenvolvimento e a população de plantas quando a lâmina de água não é eliminada por evaporação ou retirada após a semeadura. No entanto, esta prática implica maior consumo de água, retirada de nutrientes do sistema, além da reinfestação por plantas daninhas, especialmente pelo arroz vermelho.

Avaliando a utilização de água para o sistema pré-germinado, MACHADO et al. (2006) obtiveram volume de $6.216 \mathrm{~m}^{3} \mathrm{ha}^{-1}$ para todo o ciclo da cultura, onde cerca de $20 \%$ deste total foi utilizado para a formação da lâmina de água. Com isso, a drenagem inicial implica a perda de considerável volume de água, sendo este recurso limitante em algumas regiões produtoras e um dos principais itens na composição do custo de produção.

Esta mesma água utilizada para a inundação da área de cultivo antes da implantação da cultura altera as características químicas e biológicas do solo, possibilitando o aumento na disponibilidade de nutrientes. SILVA et al. (2003), avaliando a alteração da concentração de nutrientes em um Planossolo, observaram aumento nos teores de fósforo com o tempo de alagamento, decorrente do processo de redução do ferro e a conseqüente liberação do fósforo adsorvido.

Assim, os nutrientes presentes na solução do solo, oriundos das reações ocorridas após a inundação da área ou ainda os provenientes da adubação de base, efetuada antes da semeadura, podem ser carreados para fora da lavoura, em decorrência do manejo de drenagem inicial usualmente adotado.

Buscando mensurar a concentração de nutrientes perdidos através da drenagem inicial nos sistemas pré-germinado, mix de pré-germinado e transplante de mudas, WEBER et al. (2003) observaram, na média dos sistemas, perdas de 5,02; 2,06; 10,33kg $\mathrm{ha}^{-1}$ para N, P e K, respectivamente. Estas concentrações altas de nutrientes na água de drenagem podem estar ligadas ao pequeno período de tempo entre a adubação de base e a drenagem subseqüente, que foi de seis dias.

Dessa forma, constata-se que as perdas de nutrientes podem ser significativas, variando com o manejo de água adotado, afetando o ambiente através da eutrofização das águas, principalmente quando o nutriente envolvido é o fósforo (SHARPLEY et al., 2000), além de reduzir a fertilidade do solo, comprometendo a sustentabilidade do sistema.

A manutenção contínua da lâmina de água durante todo o ciclo da cultura, quando comparada à irrigação intermitente, proporciona maiores produtividades (HASSAN \& SARKAR, 1993). No entanto, ISHIY et al. (1999) citam o acamamento de plantas como maior fator limitante na adoção de lâmina contínua, pois este dificulta a colheita, minimizando o potencial produtivo e a qualidade de grãos, sendo o acamamento influenciado por diversos fatores, dentre os quais KONO (1995) cita as condições climáticas, o sistema de cultivo e a cultivar utilizada.

Neste contexto, propostas como o retardamento da drenagem inicial e a manutenção de lâmina de água de forma contínua por todo o período de cultivo assumem grande importância, pois são alternativas de manejo que podem proporcionar maior sustentabilidade ao sistema produtivo, minimizando a saída de água e nutrientes da lavoura, proporcionando maior eficiência à produção orizícola.

Com isso, conduziu-se experimentos a campo durante três safras agrícolas, objetivando avaliar diferentes manejos da água de irrigação, através da perda de nutrientes e da produtividade de cultivares de arroz irrigado no sistema pré-germinado.

\section{MATERIAL E MÉTODOS}

Os experimentos foram conduzidos nas safras agrícolas 2002/03, 2003/04 e 2004/05, na área experimental de várzea do Departamento de Fitotecnia da Universidade Federal de Santa Maria/RS, em solo classificado como Planossolo Hidromórfico eutrófico arênico. O delineamento experimental utilizado foi o de blocos casualizados, com quatro repetições, em esquema bifatorial com parcelas subdivididas. Nas parcelas principais (12 x 3m), foram dispostos os níveis do fator A (manejos da água de irrigação): [M1], retirada da água aos três dias após a semeadura; [M2], retirada da água aos 30 dias após a semeadura; [M3] = sem retirada da água, permanecendo lâmina de água contínua. Nas subparcelas ( 4 x 3m), foram alocados os níveis do fator D (cultivares), utilizando-se na safra 2002/03 as cultivares “BR-IRGA 410”, “IRGA 419” e "BRS-Taim"; na safra 2003/04, as cultivares "IRGA 419”, "BRS-Taim” e "Sabbore “e, na safra 2004/05, as cultivares “BR-IRGA410”, "IRGA420” e "BRS-Taim”.

O preparo do solo, em todos os anos, foi executado em solo seco, por meio de gradagens e posterior nivelamento superficial do terreno. Após o nivelamento, procedeu-se a construção das taipas e inundação da área, efetuada 20 dias antes da semeadura, realizada em 30/11/2002, 18/10/2003 e 23/10/2004 nas safras 2002/03, 2003/04 e 2004/05, respectivamente, utilizando-se $120 \mathrm{~kg} \mathrm{ha}^{-1}$ de sementes.

Nas safras 2002/03 e 2003/04, a adubação de base foi efetuada a lanço, 10 dias antes da

Ciência Rural, v.37, n.1, jan-fev, 2007. 
semeadura, sendo posteriormente incorporada. Já na safra 2004/05, a adubação foi efetuada a lanço, 5 dias antes da semeadura, sendo também posteriormente incorporada. As doses de fertilizantes aplicadas por ocasião da adubação de base foram: safras 2002/03 e $2003 / 04=30 \mathrm{~kg} \mathrm{ha}^{-1}$ de $\mathrm{P}_{2} \mathrm{O}_{5}$ e $60 \mathrm{~kg} \mathrm{ha}^{-1}$ de $\mathrm{K}_{2} \mathrm{O}$ e na safra 2004/05 = 40kg ha ${ }^{-1}$ de $\mathrm{P}_{2} \mathrm{O}_{5}$ e $70 \mathrm{~kg} \mathrm{ha}^{-1}$ de $\mathrm{K}_{2} \mathrm{O}$. A adubação de cobertura foi de $90 \mathrm{~kg} \mathrm{ha}^{-1}$ de $\mathrm{N}$ em todas as safras, fracionada igualmente em duas aplicações; uma no início do perfilhamento e outra na diferenciação do primórdio floral.

Por ocasião da drenagem inicial da água das parcelas, coletaram-se amostras de água drenada, em conformidade com os manejos propostos (M1 e M2). No tratamento com lâmina contínua (M3), a água foi coletada no interior da parcela em duas ocasiões, aos três e aos 30 dias após a semeadura. Na safra 2002/03, o potássio foi quantificado através de Espectrometria de Absorção Atômica por chama e o fósforo através da Cromatografia Iônica e, nas safras 2003/04 e 2004/05, as determinações de nutrientes presentes na água de irrigação foram realizadas seguindo metodologia descrita por TEDESCO et al. (1995). Além da determinação da concentração de nutrientes presentes na água de irrigação, foi avaliada a produtividade da cultura, a percentagem de plantas acamadas e de componentes de rendimento do arroz.

Para a avaliação de acamamento, foram consideradas as seguintes classes: [0] $0 \%$ de acamamento; [1] 1 a 20\% de acamamento; [2] 21 a $40 \%$ de acamamento; [3] 41 a $60 \%$ de acamamento; [4] 61 a $80 \%$ de acamamento e [5] 81 a $100 \%$ de acamamento. Por ocasião da colheita, foi feita a observação visual na área das parcelas experimentais, relacionando a porcentagem de plantas acamadas com a classe correspondente.

Os dados obtidos no experimento foram submetidos à análise de variância e as médias comparadas entre si pelo teste de Tukey em nível de $5 \%$ de probabilidade de erro.

\section{RESULTADOS E DISCUSSÃO}

Para os parâmetros avaliados na cultura do arroz irrigado, não se obteve interação significativa entre os manejos de irrigação e as cultivares utilizadas. Os manejos da água de drenagem não afetaram a produtividade e nem o acamamento de plantas nas três safras agrícolas (Tabela 1), concordando com resultados encontrados por LAURETTI et al. (2001), que não observaram diferença entre a manutenção da água durante todo o ciclo da cultura e a realização da drenagem aos três dias após a semeadura.
A média de produtividade para as safras 2002/03, 2003/04 e 2004/05 foi de $5.100 \mathrm{~kg} \mathrm{ha}^{-1}$, $9.565 \mathrm{~kg}$ ha $^{-1}$ e $7.078 \mathrm{~kg} \mathrm{ha}^{-1}$, respectivamente. Esta oscilação de rendimento deve-se ao elevado acamamento de plantas na primeira safra, na qual observou-se mais de $61 \%$ de acamamento em todas as parcelas experimentais, em decorrência de dois temporais, com chuva de alta intensidade e ventos de até $120 \mathrm{~km} \mathrm{~h}^{-1}$, quando a cultura encontrava-se no estádio de enchimento de grãos. O acamamento eleva a esterilidade de espiguetas e prejudica o enchimento de grãos, afetando o rendimento, constituindo-se em um aspecto limitante deste sistema de cultivo. Já na safra 2003/04, obtevese a maior produtividade, estando esse fato intimamente associado às condições climáticas favoráveis ao desenvolvimento da cultura, com alta disponibilidade de radiação solar e ausência de fatores capazes de provocar o acamamento de plantas.

Ressalta-se ainda que, durante o estabelecimento inicial da cultura na safra 2004/05, ocorreu um ataque de larvas da bicheira-da-raiz do arroz (Oryzophagus oryzae), tardiamente controlado através da aplicação de inseticida, o que pode ter comprometido o desempenho das cultivares utilizadas.

Neste sentido, MARCHEZAN et al. (2004), avaliando genótipos expostos a inundação contínua no sistema pré-germinado, observaram diferença entre os tratamentos para alguns parâmetros da cultura do arroz. Os autores citam que a adoção de lâmina contínua desde a inundação da área permite a obtenção de produtividades elevadas, sendo este fator influenciado pelo genótipo utilizado e pelas condições climáticas do ano agrícola. Assim, os manejos de irrigação adotados proporcionam produtividades semelhantes; no entanto, o manejo da drenagem da área, independentemente de ser realizado aos três ou 30 dias após a semeadura, através dos sucessivos anos de cultivo, provoca a redução da fertilidade do solo e do impacto ambiental negativo nos mananciais hídricos, afetando a sustentabilidade do sistema produtivo, além de aumentar o gasto de água ao longo de todo o ciclo. Além disso, a manutenção de lâmina de água durante todo o ciclo da cultura promove o controle de plantas daninhas de folha estreita, principalmente do arrozvermelho, evitando a utilização de herbicidas graminicidas, o que se constitui em aspecto econômico importante para a utilização desse manejo de irrigação.

Quando comparadas isoladamente entre si, as cultivares apresentaram diferença de produtividade apenas em 2003/04 e para acamamento em 2002/03. A tabela 2 contém dados de componentes de rendimento, onde observa-se que não houve efeito dos manejos de irrigação, estando em consonância com os resultados 
Tabela 1 - Produtividade e acamamento de plantas nas três safras, em função dos manejos propostos. Santa Maria, RS, 2006.

\begin{tabular}{|c|c|c|c|c|c|c|}
\hline \multirow[b]{2}{*}{ Tratamentos $^{1}$} & \multicolumn{3}{|c|}{ Produtividade $\left(\mathrm{kg} \mathrm{ha}^{-1}\right.$ ) } & \multicolumn{3}{|c|}{ Acamamento $^{2}$} \\
\hline & $2002 / 03$ & $2003 / 04$ & $2004 / 05$ & $2002 / 03$ & $2003 / 04$ & $2004 / 05$ \\
\hline M1 & $5447^{\text {ns }}$ & $9364^{\text {ns }}$ & $7058^{\text {ns }}$ & $4^{\mathrm{ns}}$ & 0 & 0 \\
\hline M2 & 4617 & 9628 & 7000 & 4 & 0 & 0 \\
\hline M3 & 5267 & 9704 & 7175 & 4 & 0 & 0 \\
\hline Média & 5110 & 9565 & 7078 & 4 & 0 & 0 \\
\hline CV (\%) & 16,60 & 6,80 & 3,69 & 5,4 & --- & --- \\
\hline \multicolumn{7}{|l|}{ Cultivares } \\
\hline BR-IRGA 410 & $5305^{\text {ns }}$ & --- & $7109^{\text {ns }}$ & $1 \mathrm{~b}$ & -- & 0 \\
\hline IRGA 419 & 5208 & $9522 b$ & --- & $5 a$ & 0 & --- \\
\hline IRGA 420 & -- & --- & 6971 & --- & -- & 0 \\
\hline BRS-Taim & 4818 & 10154a & 7154 & $5 a$ & 0 & 0 \\
\hline SABBORE & -- & $9018 c$ & -- & -- & 0 & --- \\
\hline Média & 5110 & 9565 & 7078 & 4 & 0 & 0 \\
\hline CV (\%) & 16,00 & 4,90 & 10,06 & 10,80 & --- & --- \\
\hline
\end{tabular}

${ }^{\text {ns }}$ Teste F não-significativo em nível de 5\% de probabilidade de erro.

Médias seguidas por mesma letra não diferem entre si pelo teste de Tukey em nível de 5\% de probabilidade de erro.

${ }^{1}$ M1: retirada da água aos três dias após a semeadura; M2: retirada da água aos trinta dias após a semeadura e M3: sem retirada da água, com manutenção de lâmina contínua.

${ }^{2}$ Escala utilizada para avaliação: onde [0] 0\% de acamamento; [1] 1 a 20\% de acamamento; [2] 21 a 40 \% de acamamento; [3] 41 a 60 \% de acamamento; [4] 61 a $80 \%$ de acamamento e [5] 81 a $100 \%$ de acamamento.

Tabela 2 - Grãos por panícula (GPP), esterilidade de espiguetas e massa de mil grãos (MMG) nas três safras, em função dos manejos propostos. Santa Maria, RS, 2006.

\begin{tabular}{|c|c|c|c|c|c|c|c|c|c|}
\hline \multirow[b]{2}{*}{ Tratamentos $^{1}$} & \multicolumn{3}{|c|}{ GPP } & \multicolumn{3}{|c|}{ Esterilidade (\%) } & \multicolumn{3}{|c|}{ MMG (g) } \\
\hline & 02/03 & 03/04 & $04 / 05$ & $02 / 03$ & 03/04 & $04 / 05$ & $02 / 03$ & 03/04 & $04 / 05$ \\
\hline M1 & $99^{\text {ns }}$ & $74^{\mathrm{ns}}$ & $98^{\text {ns }}$ & $22^{\text {ns }}$ & $14^{\mathrm{ns}}$ & $11^{\mathrm{ns}}$ & $25^{\mathrm{ns}}$ & $27^{\mathrm{ns}}$ & $27^{\text {ns }}$ \\
\hline M2 & 91 & 84 & 99 & 20 & 14 & 11 & 26 & 27 & 27 \\
\hline M3 & 88 & 78 & 99 & 22 & 14 & 10 & 26 & 27 & 27 \\
\hline Média & 93 & 79 & 99 & 21 & 14 & 11 & 25 & 27 & 27 \\
\hline CV (\%) & 10,30 & 15,70 & 4,79 & 15,70 & 19,00 & 11,02 & 3,65 & 6,93 & 2,18 \\
\hline \multicolumn{10}{|l|}{ Cultivares } \\
\hline BR-IRGA 410 & $105 a$ & --- & $101 \mathrm{a}$ & $24^{\mathrm{ns}}$ & --- & $10^{\mathrm{ns}}$ & $26^{\mathrm{ns}}$ & --- & $27^{\mathrm{ns}}$ \\
\hline IRGA 419 & $79 b$ & $80 \mathrm{a}$ & -- & 20 & $14 \mathrm{ab}$ & -- & 26 & 27 & -- \\
\hline IRGA 420 & --- & --- & $95 b$ & --- & --- & 11 & --- & --- & 27 \\
\hline BRS-Taim & $95 a b$ & $88 a$ & $100 \mathrm{ab}$ & 20 & $17 \mathrm{a}$ & 11 & 25 & 26 & 27 \\
\hline SABBORE & --- & $68 \mathrm{~b}$ & --- & --- & $11 \mathrm{~b}$ & --- & --- & 27 & --- \\
\hline Média & 93 & 79 & 99 & 21 & 14 & 11 & 25 & 27 & 27 \\
\hline CV (\%) & 16,40 & 11,70 & 5,61 & 14,80 & 13,90 & 7,07 & 5,91 & 7,13 & 2,18 \\
\hline
\end{tabular}

${ }^{\text {ns }}$ Teste F não-significativo em nível de 5\% de probabilidade de erro.

Médias seguidas por mesma letra não diferem entre si pelo teste de Tukey em nível de 5\% de probabilidade de erro.

${ }^{1}$ M1: retirada da água aos três dias após a semeadura; M2: retirada da água aos trinta dias após a semeadura e M3: sem retirada da água, com manutenção de lâmina contínua.

Ciência Rural, v.37, n.1, jan-fev, 2007. 
de produtividade. Com relação às cultivares utilizadas na safra 2002/03, observou-se diferença entre "BRIRGA 410” e “IRGA 419” para grãos por panícula. Na safra 2003/04, constatou-se diferença significativa entre as cultivares utilizadas para grãos por panícula, onde “BRS-Taim” e "IRGA 419" superaram a cultivar "Sabbore”, e para esterilidade de espiguetas, onde a cultivar "BRS-Taim” diferiu da cultivar "Sabbore”, que apresentou a menor porcentagem de espiguetas estéreis. Na safra 2004/05, a cultivar "BR-IRGA 410" apresentou maior número de grãos por panícula, quando comparada com a cultivar "IRGA 420", sendo a cultivar "BRS-Taim" semelhante a "BR-IRGA 410" e "IRGA 420". Mesmo observando diferença entre as cultivares para alguns parâmetros avaliados, os manejos testados não diferiram, evidenciando a possibilidade de utilização e de escolha de genótipos mais bem adaptados à cada região de cultivo, bem como a capacidade de compensação da produtividade pela flexibilidade de resposta das cultivares aos diversos parâmetros constituintes da produtividade.

Para o estande inicial de plantas, não foi observada diferença estatística entre manejos e cultivares em nenhum ano de realização do estudo (dados não mostrados), ficando a média em 320, 304 e 413 plantas $\mathrm{m}^{-2}$, para as safras 2002/03, 2003/04 e 2004/ 05 , respectivamente, concordando com resultados de MARCOLIN \& MACEDO (2001). Esses autores, avaliando o efeito da lâmina de água na população inicial e final de plantas e no rendimento de grãos no sistema pré-germinado, concluíram que a drenagem inicial pode ser feita até cinco dias após a semeadura sem redução da produtividade, bem como que não há necessidade de realizá-la caso o solo tenha sido preparado sem a presença de lâmina de água, como foi efetuada nos três anos do experimento.
Com relação à concentração de nutrientes na água de irrigação, observou-se que, nas safras 2002/ 03 e 2003/04, as perdas de fósforo não apresentaram diferença significativa, independentemente do momento de coleta das amostras (Tabela 3). No entanto, foi observado comportamento distinto na safra 2004/ 05 , em que as concentrações de fósforo foram influenciadas pelos manejos propostos, constatandose concentrações maiores nas amostras coletadas aos três dias após a semeadura. Observa-se ainda que as concentrações de fósforo, nutriente de grande impacto ambiental, estão abaixo do valor máximo estabelecido pela Secretaria da Saúde e do Meio Ambiente (RIO GRANDE DO SUL, 1989), que limita em 1,0 $\mathrm{mg} \mathrm{L}^{-1}$ a concentração de fósforo para efluentes líquidos que possivelmente possam ser lançados em corpos d’água, embora, na última safra, as concentrações tenham sido bastante superiores. Este fato pode estar associado ao maior volume de fertilizante aplicado e ainda ao menor tempo entre a adubação e a drenagem subseqüente. Por outro lado, tem-se que as concentrações de fósforo obtidas na safra 2004/05 situam-se acima do limite estabelecido pela Resolução nº 357 do CONAMA (2005) para águas de classe 1 , onde os teores não deveriam exceder $0,025 \mathrm{mg} \mathrm{L}^{-1}$. Instituições de estudos ambientais como a EPA (2004) consideram limites variávies para cada região dos Estados Unidos, orientando no sentido de que os limites para $\mathrm{P}_{\text {total }}$ não devam ser superiores a $0,128 \mathrm{mg} \mathrm{L}^{-1}$.

Para potássio, nos três anos de condução do experimento, constataram-se maiores concentrações nas amostras coletadas aos três dias após a semeadura, tanto nas parcelas onde efetuou-se a drenagem (M1), como naquelas onde a lâmina de água foi mantida (M3). Nas coletas efetuadas aos 30 dias após a semeadura,

Tabela 3 - Concentração de fósforo (P) e de potássio (K) na água de irrigação coletada nas três safras, em função dos manejos propostos. Santa Maria, RS, 2006.

\begin{tabular}{|c|c|c|c|c|c|c|}
\hline \multirow{2}{*}{ Tratamentos $^{1}$} & \multicolumn{3}{|c|}{$\mathrm{P}\left(\mathrm{mg} \mathrm{L}^{-1}\right)^{2}$} & \multicolumn{3}{|c|}{$\mathrm{K}\left(\mathrm{mg} \mathrm{L}{ }^{-1}\right)^{2}$} \\
\hline & 2002/03 & $2003 / 04$ & $2004 / 05$ & $2002 / 03$ & $2003 / 04$ & $2004 / 05$ \\
\hline M1 & $0,007^{\mathrm{ns}}$ & $0,021^{\mathrm{ns}}$ & $0,516 a$ & $2,45 \mathrm{a}$ & $5,1 \mathrm{a}$ & $15,6 \mathrm{a}$ \\
\hline M2 & $<0,001$ & 0,018 & 0,180b & $1,23 \mathrm{~b}$ & $1,5 \mathrm{~b}$ & $5,4 \mathrm{~b}$ \\
\hline M3 (3dias) & $<0,001$ & 0,020 & $0,522 \mathrm{a}$ & 2,94 a & 5,8 a & 16,0 a \\
\hline M3 (30 dias) & 0,007 & 0,025 & $0,261 b$ & $1,40 \mathrm{~b}$ & $1,3 \mathrm{~b}$ & $5,2 \mathrm{~b}$ \\
\hline Média & 0,004 & 0,021 & 0,377 & 2,00 & 3,4 & 10,55 \\
\hline CV (\%) & 0,75 & 0,7 & 20,97 & 5,1 & 12,5 & 8,91 \\
\hline
\end{tabular}

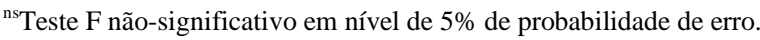

Médias seguidas por mesma letra não diferem entre si pelo teste de Tukey em nível de 5\% de probabilidade de erro.

${ }^{1}$ M1: amostras coletadas aos três dias após a semeadura, no momento da drenagem; M2: amostras coletadas aos 30 dias após a semeadura, no momento da drenagem; M3 (3 dias): amostras coletadas aos três dias após a semeadura, no interior das parcelas e M3 (30 dias): amostras coletadas aos 30 dias após a semeadura, no interior das parcelas.

${ }^{2}$ Para análise, dados transformados para: $\sqrt{\mathrm{x}+0,5}$. 
nas parcelas com drenagem (M2) e com lâmina contínua (M3), observaram-se concentrações menores deste nutriente, indicando que houve decantação e/ou absorção pelas plantas de arroz, em decorrência do maior período de tempo transcorrido. MARCHEZAN et al. (2001), analisando a perda de nutrientes em diferentes manejos de adubação para o sistema prégerminado, encontraram perdas médias de $5,7 \mathrm{mg} \mathrm{L}^{-1}$, valor acima dos observados nas safras 2002/03 e 2003/ 04, respectivamente, de 2,0 e 3,4mg L-1, mas abaixo da concentração média obtida em 2004/05, que foi de $10,55 \mathrm{mg} \mathrm{L}^{-1}$, mostrando que as perdas de potássio são influenciadas por fatores de manejo como quantidade de fertilizante aplicado, incorporação ou não do adubo e ainda tempo entre a realização da adubação e a da drenagem subseqüente.

\section{CONCLUSÃO}

A manutenção de lâmina de água durante todo o ciclo da cultura não afeta a produtividade do arroz irrigado no sistema pré-germinado, reduzindo o consumo de água e a perda de nutrientes.

\section{AGRADECIMENTOS}

Ao Conselho Nacional de Desenvolvimento Científico e Tecnológico (CNPq), à Fundação de Amparo à Pesquisa do Estado do Rio Grande do Sul (FAPERGS) e à Universidade Federal de Santa Maria (UFSM), pelo apoio financeiro concedido para a execução do trabalho de pesquisa.

\section{REFERÊNCIAS}

CONAMA, Conselho Nacional de Meio Ambiente. Brasília, 2005. (Resolução CONAMA n. 357, de 17 de março de 2005).

EPA, Environmental Protection Agency. CleanWater Act. Water Science. Water Quality Criteria. Nutrients. Acessado em: 03 de dezembro de 2004. On line. Disponível em:http://www.epa.gov/waterscience/criteria $>$.

HASSAN, A.A.; SARKAR, A.A. Yield and water use efficiency of newly developed rice mutants under different water management practices. International Rice Research Notes, Manila, v.18, n.2, p.34, 1993.

ISHIY, T. et al. Comportamento de linhagens e cultivares de arroz submetidas a condições de inundação permanente. In:
REUNIÃO DA CULTURA DO ARROZ IRRIGADO, 23., 1999, Pelotas, RS. Anais... Pelotas: Embrapa Clima Temperado, 1999. p.117-119.

KONO, M. Phsysiological aspects of lodging. In: MATSUO, T. et al. Science of the rice plant. Tokyo, Japan: Nobunkyo, 1995. V.2, cap.4, p.971-982.

LAURETTI, R.L.B. et al. Efeitos de diferentes manejos de água no estabelecimento de plantas de arroz no sistema prégerminado. Pesquisa Agropecuária Brasileira, v.36, n.9, p.1093-1099, 2001.

MACHADO, S.L.O. et al. Consumo de água e perdas de nutrientes e sedimentos na água de drenagem inicial do arroz irrigado. Ciência Rural, v.36, n.1, p.65-71, 2006.

MARCHEZAN, E. et al. Desempenho de genótipos de arroz irrigado cultivados no sistema pré-germinado com inundação contínua. Ciência Rural, v.34, n.5, p.1349-1354, 2004.

MARCHEZAN, E. et al. Manejo da adubação do arroz irrigado em sistema pré-germinado na produtividade e na perda de nutrientes através de drenagem inicial. Ciência Rural, Santa Maria, v.31, n.5, p.877-879, 2001.

MARCOLIN, E.; MACEDO, V.R.M. Manejo da drenagem inicial e sua relação com a população de plantas e rendimento de grãos de arroz no sistema pré-germinado. In: CONGRESSO BRASILEIRO DE ARROZ IRRIGADO, 2.; REUNIÃO DA CULTURA DO ARROZ IRRIGADO, 24., 2001, Porto Alegre, RS. Anais... Porto Alegre: Instituto Rio Grandense do Arroz, 2001. p.227-228.

RIO GRANDE DO SUL. Portaria número 05/89 de 16 de março de 1989 - SSMA. Aprova a Norma Técnica, que dispõem sobre critérios e efluentes líquidos... Diário Oficial, Porto Alegre, 29 de março de 1989.

SHARPLEY, A. et al. Practical and innovative measures for the control of agricultural phosphorus losses to water: an overview. Journal of Environmental Quality, v.29, n.1, p.1-9, 2000.

SILVA, L.S. da et al. Alterações nos teores de nutrientes em dois solos alagados, com e sem plantas de arroz. Ciência Rural, v.33, n.3, p.487-490, 2003.

TEDESCO, M.J. et al. Análises de solo, plantas e outros materiais. 2.ed. Porto Alegre: UFRGS, Faculdade de Agronomia, Departamento de Solos, 1995. 174p. (Boletim Técnico de solos, 5).

WEBER, L. et al. Cultivares de arroz irrigado e nutrientes na água de drenagem em diferentes sistemas de cultivo. Ciência Rural, v.33, n.1, p.27-33, 2003. 